\title{
Práticas sociais das perversões: modernidade do laço, organização social e dilemas morais*1
}

\author{
Alexandre Lévy*2
}

Propomos estudar primeiramente certos aspectos do discurso capitalista, aproximando-os dos processos perversos da clínica do sujeito para, em seguida, questionar a dimensão da moral e da construção social. Apoiaremo-nos em algumas pesquisas experimentais sobre a submissão à autoridade, bem como sobre algumas questões postas pela filosofia moral em termos de "dilemas", a fim de avaliar os efeitos de divisão subjetiva. A orientação perversa parece ser aqui um motor essencial, fazendo passar, em nome do Outro, um gozo que não diz seu nome, um gozo desmentido.

Palavras-chave: Perversão, gozo, submissão, moralidade

*1 Texto de um trabalho apresentado no Colóquio Internacional sobre Metapsicologia da Perversão. Usos Sociais da Perversão, ocorrido de 26 a 28 de agosto de 2013, Universidade Católica de Pernambuco - Unicap (Recife, PE, Br.).

*2 IPSA, Institut de psychologie appliquée, Université Catholique de l'Ouest - UCO, Angers (França). 
Após os nossos comentários preliminares enunciados previamente, vamos primeiramente aprofundar a questão das práticas da perversão numa certa modernidade do laço social, para depois tratar das suas consequências sobre a organização social e de alguns dilemas morais que daí podem resultar.

A partir das observações clínicas, conseguimos separar alguns processos específicos da estrutura perversa. Em primeiro lugar, a função central do fantasma como instrumento previamente requerido que orienta um mecanismo.

Às vezes, o sujeito perverso pode se apresentar como uma espécie de descobridor dos talentos polimorfos do "parceiro", o qual faz o papel de cândido, até mesmo de candidato. Relativo à função cândida, a figura de Justine do Marquês de Sade (Sade, 1791/1993) parece representar um paradigma pertinente. Justine é a vítima ideal, sempre presa, sempre pronta e submetida à vontade dos seus atormentadores, assim como ao seu saber, a fim de iniciá-la aos vícios e virtudes: e, muitas vezes, na maior ambiguidade, ela aceita.

Relativo à posição do candidato, certos programas de televisão, chamados de telerrealidade, parecem acumular todas as características de uma encenação orientada de maneira perversa. O objetivo é de mostrar, até mesmo de fazer a "mostração", do espetáculo, nos revelando o menor dos afetos dos candidatos/ concorrentes, que seja com a divulgação dos castings ou com provas ligadas a um mecanismo de submissão. Ao mesmo tempo estes shows apresentam ao telespectador as situações de experimentação como uma "aventura".

Esta encenação racionalmente organizada tem um lado lúdico - o mesmo que na ameaça sádica, na qual, para resumir, a eficiência depende da credulidade do parceiro frente a um: 


\section{ARTIGOS}

“cuidado, vou te machucar!". O que importa é prender o parceiro com o gozo ligado ao seu fantasma e, portanto, dividi-lo até o ponto de causar a sua angústia.

A estrutura perversa contém também um fetichismo fundamental, ligado à fixação libidinal, a orientação da busca perversa sendo de submeter o objeto para depois restituí-lo ao Outro e obturar assim a hiância radical da castração (Lacan, 1969/1991, p. 292). Com esse processo, o sujeito assimila a ideia de ser plenamente capaz para satisfazer o Outro, um Outro que foi primeiramente Outro materno.

Uma outra especificidade da orientação perversa reside numa certa vocação ou paixão para o objeto e seu desvelamento. Podemos então conceber uma persistência do sujeito perverso a extrair e por a nu o objeto interno, a fim de garantir para sempre a sua posição central no coração do desejo, ou seja, ser identificado à figura imaginária do falo. Essa persistência no desvelamento do objeto se explica com o desmentido da castração que este objeto tem, como função, obturar.

\section{Da modernidade do laço: o discurso do capitalista}

Vamos fazer uma transposição no plano social e tentar destacar os registros do fetichismo, do desmentido e da persistência na busca do gozo, um gozo literalmente integrado num certo tipo de discurso, em particular o do capitalista, que oferece e banaliza esta dimensão perversamente orientada como padrão possível dos encontros e do intercâmbio entre os sujeitos.

Este discurso é uma versão distorcida do discurso clássico do mestre que, em vez de salientar o significante-mestre como um princípio ou um lema, faz a promoção da falta e da divisão subjetiva para poder depois tirar vantagem da situação.

Este discurso é inteiramente baseado numa exploração feroz do desejo, cativando-nos com a perspectiva de um gozo mítico e sempre renovado. Portanto, os objetos de consumo representam alguns prazeres possíveis, potenciais. Basta anunciá-los como tais por meio de um slogan publicitário - esses significantes publicitários que têm a mesma eficiência e funcionam da mesma maneira que o inconsciente, graças à insistência, ao ritmo e à repetição às vezes debilitante destinada a afetar o "parlêtre" - para criar um prazer, provavelmente o único que jamais experimentará, um prazer por procuração que nunca atingirá, em referência ao gozo mítico. A este propósito, Jacques Lacan (1971/2001) nota: "é exatamente a mesma coisa [que o discurso do mestre], só que é mais bem-feito, funciona melhor, vocês estão ainda mais engabelados" (p. 292).

O desmentido reside no que pode ser visto como um princípio orientador, uma injunção da lei do mercado: a de satisfazer o cliente ou usuário. "Satisfeito ou reembolsado!": uma espécie de fórmula mágica — que também é uma ordem 
- que prevê qualquer desvio a cumprir a promessa capitalista, promessa de uma completude que tem tudo de um ato de fé. Esta fórmula ressoa como um semblante de cruzada moderna, liderada pelo imperativo e o império da satisfação. Esses significantes insistentes, injuntivos, agindo no superego, se tornam os significantes-mestres aos quais o sujeito adere e se subordina, ${ }^{1}$ até que capitule e desvaneça, levado pela força de convicção que eles carregam.

O slogan publicitário: "Sonhei com isso, a Sony faz!", que invadiu as mídias francesas há alguns anos, é um outro exemplo desse tipo de discurso. A fórmula, sem dúvida um achado, é paradigmática da exploração do desejo. Ela tem um efeito universal, pois a falta é anunciada desde o início com o "Sonhei com isso", o seu sonho não sendo mais do que um pálido e ridículo testemunho da falta que a marca Sony compromete-se a satisfazer, realizando assim a completude que antes faltava ao sujeito. No fundo, este prenchimento da falha é a promessa para o "parlêtre" do acontecimento da relação sexual, e ele é ao mesmo tempo industrial, capitalista e religioso. A utilização do desmentido nesta exploração do sujeito é patente e agora generalizada.

Deste ponto de vista, a análise de Guy Debord no seu livro A sociedade do espetáculo aparece como uma das mais pertinentes, particularmente porque é uma continuidade dos pensamentos de Karl Marx, em 1867, sobre o fetichismo da mercadoria (Debord, 1967, p. 21) — este fetichismo que designa a mercadoria como suporte alienante do laço social entre os homens, substituindo assim a qualquer outro tipo de laço (Marx, 1867/1993, p. 81). Guy Debord (1967) conceptualiza o espetáculo como uma extensão dessa noção. Porém, este ensaio político, uma obra importante e visionária da nossa sociedade de consumo neoliberal e agora globalizada, não atinge o seu alvo, a intenção implícita do autor sendo de prejudicar a sociedade espetacular. De fato, apesar da exatidão da sua análise e de suas predições sobre a evolução da economia do espetáculo — da qual ele demostra a terrível eficiência - Guy Debord nos deixa como única alternativa a impotência de uma luta direta e frontal, sem aprofundar as problemáticas subjetivas que alimentam e respondem à eficiência do espetáculo.

$\mathrm{Na}$ verdade, ninguém pode escapar deste circuito do objeto mercantil, objeto não só fetichizado, mas também objeto "lathouse", um termo inventado por Lacan. A lathouse, ${ }^{2}$ avatar do objeto fálico na sua dimensão de gadget, descreve um objeto cuja função é de ser esquecida, escamoteada, pois ele é feito para pulular e se

${ }^{1}$ Ainda mais porque este tipo de relações permite um regulamento servil do indivíduo através da cultura do supereu.

${ }^{2}$ Etimologicamente, este neologismo vem do greco lethe (de aletheia), significando "esquecimento", combinado com ousia, ou seja, "a substância, a essência". 
renovar num mundo mercantil (Lacan, 1970/1991, p. 189) governado pelas ciências aplicadas. Impossível de escapar, dizíamos, do mecanismo das latusas, porque seria não só renunciar ao fantástico fantasma de reparação, que é a noção de serviço pós-venda, de seguro e de troca padrão, mas também à sujeição segura que promete este discurso. Não podemos subestimar o sonho de perversão do neurótico (Lacan, 1972/1975, p. 80), neste caso um sonho de objetivação e de instrumentalização de si mesmo, que elimina as marcas de toda divisão subjetiva.

A noção de biopoder exposta por Michel Foucault (1976) seria neste caso esclarecedora se a associamos às consequências do discurso capitalista. Desde a época dos mestres antigos, o poder do dominus se exerce tradicionalmente como patria potestas (poderes paternais), ou seja, com o direito de vida e de morte do senhor sobre a sua famíla e seus sujeitos. Resultado de uma transformação deste poder antigo, o biopoder se exerce como controle e regulação da vida e do vivo (p. 183). O direito de matar se transformou em poder de investimento, gestão e administração de todos os aspectos do vivo, a fim de tornar perene a autoridade das instituições.

Há na sociedade do lazer, das férias e do divertimento exemplos concretos da dimensão administrativa e injuntiva da alegria do entertainment. Trata-se de uma lógica dos campos, lógica renovada, que Jacques Lacan descreve como não só a herança da Segunda Guerra Mundial, mas também como a vanguarda do progresso da administração e do management (Lacan, 1967). Por isso, o biopoder, regulação implacável do vivo, reduzindo o ser humano a um fator na equação administrativa, permite reatualizar a fórmula imperativa, porém irônica, do Marquês de Sade: "Mais um esforço!". A persistência que nós evocávamos a propósito da busca perversa encontra-se de várias maneiras nesta gerência implacável do vivo.

\section{Da organização social: a submissão à autoridade}

Este aspecto nos permite analisar as práticas perversas presentes na organização social. Vamos nos basear na experiência de psicologia desenvolvida por Stanley Milgram entre 1950 e 1963, destinada a medir o grau de obediência, para ilustrar o nosso propósito.

A nossa intenção não é entrar nos detalhes desta famosa experiência, mas sublinhar os resultados obtidos. Eles revelam que um pouco mais de dois terços dos candidatos obedeceram até o fim à autoridade. Para Milgram (1974), isso significa que a obedência é doravante parte integrante do comportamento social (p. 158). Do ponto de vista cibernético, adotado pelo autor, o estado de obediência se exprime como um "estado agêntico" (p. 166). Agente ativo da experiência, o sujeito é submetido a um princípio de autoridade externo e acaba deixando a sua 
responsabilidade na mão dele. Este estado agêntico se opõe ao estado autônomo, no qual o sujeito estima ser responsável por seus atos.

Milgram nota também que o fenômeno de tensão e de ansiedade do participante durante o experimento é essencialmente um fenômeno de regulação que tem como finalidade fazer perdurar o estado agêntico e ao mesmo tempo mostrar a sua desaprovação (por exemplo, por meio de reações físicas como transpiração, tremores e ataques de riso nervosos).

Preocupado em não atrapalhar o experimento e, portanto, a obediência, o indivíduo faz de tudo para atenuar a tensão, de sorte que, quanto mais a tecnologia usada para executar a tarefa é impessoal e afasta o participante da vítima, mais ele se desapega dela, fazendo assim perdurar a situação agêntica. Existe um "contraste flagrante entre o campo da lógica e o da psicologia", nota Milgram, pois apertar botões ou manetes tende a neutralizar o senso moral, o que não aconteceria se o participante estivesse frente a frente com a vítima, como, por exemplo, se tivesse que bater num aluno para puní-lo.

O experimento de Milgram é essencialmente uma experiência sobre o sujeito e a sua relação ao Outro (com maiúscula), o Outro e a causa dele. Porém, apesar da pertinência das suas observações sobre o estado agêntico, parece-nos que os mecanismos psíquicos das relações não foram apreendidos, porque a noção de sujeito dividido e sua relação ao gozo não foi considerada. Todavia, o estudo da relação agêntica e dos fenômenos de tensão crescente durante a experiência permite se aproximar das manifestações de divisão do sujeito preso numa relação de gozo que só pode experimentar-se como consequência do dispositivo cujo Outro experimentador é a caução. Uma das interrogações que esta experiência levanta pode se enunciar assim: como participar do dispositivo do Outro, submetendo-se às suas exigências, e ao mesmo tempo ser sensível aos sinais de gozo que decorrem do fato de ser submetido à vontade do Outro?

Existe de fato uma certa prática social do superego, neste caso personificado pelo Outro da ciência, ${ }^{3}$ encarnando uma forma de imperativo de gozo. ${ }^{4} \mathrm{O}$ sujeito deve conformar-se com a vontade de gozo (ou tentar se livrar dela), uma vontade tácita, porque a causa explícita sempre é outra, neste caso é em nome da ciência que o dispositivo de Milgram se apresenta. Assim, este gozo implícito, desmentido, fica no centro dos fenômenos revelados pela experiência de submissão à autoridade.

${ }^{3}$ Uma nova versão da experiência de Milgram foi realizada na França em 2009, sob a forma de um programa de televisão em que os atributos da autoridade do Outro foram modificados, passando da ciência ao espetáculo.

${ }^{4}$ Uma das caraterísticas do supereu é contida no imperativo: «goze!», como diz Lacan (1972, p. 10). 


\section{ARTIGOS}

Obedecer é para o sujeito um meio de afinar o seu gozo à causa do Outro, de manter a ligação com ele, enquanto a desobediência é uma ruptura radical com o Outro e seu dispositivo. Desobedecer acaba com a tensão, mas não é um ato fácil, porque muda profundamente a relação do sujeito com a autoridade, alterando o comportamento social conveniente num tipo de relação desconhecida, numa anomia pontual e local (Milgram, 1974, p. 202). Portanto, a tomada de consciência ligando à ideia da desobediência não é suficiente para provocá-la. Milgram relata o processo desta forma: dúvida interior, exteriorização da dúvida, desaprovação.

Há uma falha epistemológica entre a desaprovação e a desobediência, embora as duas noções pareçam convergir. Se a maior parte dos sujeitos desaprova abertamente o jeito de conduzir a experiência, poucos chegam a desobedecer. Porque $o$ ato de desobediência tira o sujeito da passividade da submissão, obrigando-o a assumir a sua implicação no dispositivo, enquanto, na maioria dos casos, o sujeito conta com o experimentador para interromper o processo e libertar a vítima. Desobedecer é, portanto, um ato de destruição da experiência: o sujeito rebelde entra em conflito com o discurso caucionado pelo Outro e acaba geralmente se sentindo culpado de trair a ciência e as relações sociais envolvidas. A pequena porcentagem de desobediência observada durante a experiência pode ser assim explicada: o sujeito submetido ao discurso do Outro consegue lidar com o gozo de forma regulada, enquanto aquele que desobedece, privado do apoio do discurso do Outro, tem de enfrentá-lo de modo subjetivo.

Uma outra situação da experiência de Milgram nos parece interessante. É o caso em que o sujeito nega a sua responsabilidade para atenuar a tensão. Isso acontece geralmente depois que o experimentador intervém para garantir ao candidato que ele não será culpado pelas consequências do dispositivo. A forma projetiva da negação da responsabilidade permite, por exemplo, encontrar uma explicação e, ao mesmo tempo, regular pontualmente a relação com o gozo. $\mathrm{O}$ sujeito põe então a culpa no aluno em dificuldade. "Ele é incriminado por ter aceitado voluntariamente fazer esta experiência e", acrescenta Milgram (1974), "criticado com certa perfídia para a sua estupidez e sua teimosia. Passamos aí da transferência da responsabilidade à denigração da vítima. O mecanismo psicológico é óbvio: se o aluno é um ‘burro', ele tem o que merece!” (p. 199).

Esta tendência reatualiza a fase sádica do famoso fantasma estudado por Freud (1919/1973), "Uma criança é espancada", que podemos resumir assim: "O pai [meu pai] bate a criança [odiada por mim]" (p. 225). Da mesma maneira que no dispositivo experimental de Milgram, a tensão subjacente a este enunciado fantasmático é tripla. Lacan (1956/1994, p. 116) a descreve assim: temos o pai como agente do castigo (personificado na experiência de Milgram pelo experimentador), a criança que apanha (o aluno-vítima) e o sujeito, terceira pessoa, que olha a cena de fora. Traduzindo, o aluno que recebe os choques elétricos tem a função de instrumento, de 
objeto mediador da relação entre o Outro experimentador e o sujeito que olha e se torna agente executivo da vontade do Outro.

Esta maneira de depreciar a vítima, chegando até a insultá-la, revela que esta manifestação clara da inclinação perversa é uma tentativa para o sujeito de abolir a relação simbólica com o aluno. O mais a subjetividade do pequeno outro (o aluno-vítima, embora semelhante) é reduzida - ao ponto de mantê-lo ao estado de "puro signo" (p. 119) —, o mais a sua própria subjetividade é facilmente deixada para trás, neutralizada, reduzida também a um instrumento, permitindo assim o gozo do Outro.

\section{Do dilema moral}

Alguns aspectos da experiência de Milgram foram mais especificamente estudados no campo da filosofia moral e, mais tarde, nesta disciplina especificamente anglo-saxônica que é a psicologia moral.

A filósofa Philippa Foot, seguida por Judith Jarvis Thomson, desenvolveu os cenários dos dilemas morais que se tornaram, mais tarde, protocolos experimentais usados para avaliar, via cadeia de meios e fins, o grau de aceitabilidade moral de uma situação e extrair dos resultados as propriedades de uma moral universal (como nos preceitos de Kant).

O mais famoso desses cenários recebeu o nome de "dilema do bonde" (the trolley dilemna). Ele pode se resumir assim: o motorista de um bonde descobre que os freios quebraram e que o trem encaminha-se a alta velocidade em direção a cinco homens trabalhando nos trilhos. O motorista tem, contudo, a possibilidade de desviar o trem para um trilho lateral, onde encontra-se um único indivíduo. A questão é a seguinte: é moralmente aceitável fazer desviar o bonde? (Foot, 1967/1997, p. 160).

Segundo P. Foot, teríamos a intuição de que parece moralmente aceitável desviar o bonde e sacrificar uma vida para salvar cinco. Mas num cenário diferente, no qual um médico poderia salvar cinco pessoas retirando os órgãos de uma pessoa sacrificada, a intuição da aceitabilidade moral não é a mesma. As questões levantadas por Philippa Foot são: onde está fundamentalmente a diferenca entre os dois tipos de dilemas? Existe uma contradição entre as intuições? Como justificá-las (Ogien, 2011, p. 75).

Judith Jarvis Thomson (1976/1986) prosseguiu o trabalho de P. Foot e desenvolveu várias variantes do dilema para reforçar seus efeitos (p. 78). ${ }^{5} \mathrm{~A}$ versão chamada "fat man" se resume assim: o bonde sem freios é lançado a toda

${ }^{5}$ Em particular, numa das suas publicações cujo título pode-se traduzir por "Matar, deixar morrer ou o problema do bonde". 


\section{ARTIGOS}

velocidade em direção aos cinco trabalhadores que estão nos trilhos. Estamos numa ponte, em cima da estrada de ferro, do lado de um indivíduo com sobrepeso ( $f a t$ man). Se empurrássemos o homem da ponte, ele morreria, mas o corpo dele pararia o bonde. Isso é moralmente aceitável?

Numa outra versão, não precisaríamos empurrar o obeso, mas simplesmente acionar uma alavanca para desviar o bonde, que será depois parado pelo corpo do homem. Isso é moralmente aceitável?

Usando o que Milgram chama de "amortecedores de tensão", os resultados de Thomson mostram que a maior parte dos sujeitos, respondendo à questão colocada pelo dilema, acha aceitável acionar a alavanca, mas não empurrar o homem. Para o autor, esta "assimetria moral" concorda com a intuição e ela é universal. Enquanto utilizar o corpo do seu próximo como meio seria uma violação dos direitos fundamentais, acionar uma alavanca é mais uma maneira de "desviar a fatalidade" (Ogien, 2011, p. 78). Um protocolo experimental derivado destes dilemas tem sido organizado via internet pelo biologista Marc Hauser e sua equipe. $\mathrm{O}$ dispositivo permitiu o recolhimento das respostas de 2.600 sujeitos que confirmaram os resultados de Thomson e levaram a equipe a concluir a universalidade desta assimetria moral (Hauser et al., 2007).

Esta breve apresentação dos dilemas morais suscita, porém, alguns comentários.

Primeiramente, sobre a problemática questão da escolha: na sua essência, a alternativa proposta pelo dilema moral sempre é imposta, porque a nossa relação ao gozo é modificada desde que entramos no dispositivo. Em outras palavras, a partir do momento em que devemos responder ao dilema, nos tornamos reféns de um processo de submissão implícito que nos incorpora subjetivamente na situação, obrigando-nos a aderir tacitamente à causa final, o imperativo: "parar o bonde". Por isso, a participação ao dilema se resume essencialmente a se submeter à causa imperiosa do Outro para pôr à prova a sua divisão subjetiva.

Além do mais, o dilema moral é baseado numa ideologia precisa e fortemente marcada, neste caso uma concepção utilitarista do homem pelo homem, apoiada não só no que chamamos "a moral" (porque teria que aprovar uma quantificação da morte para avaliar o nível de moralidade: temos de escolher entre uma morte ou cinco), mas também na relação de gozo subjacente à experiência (onde a questão é saber como gozar do corpo do outro de uma maneira aceitável para a moral e usar de metonímia na sua utilização para resolver a situação e evitar assim a confrontação com a sua própria implicação subjetiva).

Fundamentalmente, o dispositivo do dilema moral resume-se a uma escolha binária que põe em evidência a divisão subjetiva, isso num contexto de desmentido da implicação do Outro.

O questionamento sobre a moral e seus princípios permite, neste caso, provocar um gozo no logo desmentido, gozo tomado no sujeito afetado, no nome de princípios estabelecidos, enunciados pelo Outro. 
Por este motivo, tentar responder esse dilema nos coloca num dispositivo de tipo sadiano, em que a moralidade serve acima de tudo de véu das tendências perversas, um véu que tem a dupla função de cobrir e de sustentar a dimensão perversamente orientada do dispositivo. O dilema moral é então uma colocação insidiosa do véu no gozo do Outro, um Outro cuja causa implícita, porém urgente, é "parar o bonde", uma causa colocada como pedra angular do dilema.

Vamos agora emitir uma hipótese: examinando o que é contido de maneira condensada no dilema moral e o que regula as práticas sociais numa orientação perversa, concluímos que o gozo esperado, provocado, é um gozo de tipo unité ratière, uma expressão criada por Lacan $(1973 / 1975$, p. 127) que se refere ao rato de laboratório posto à prova num labirinto experimental. A unité ratière é, portanto, o rato visto como corpo a provar, e é também a redução do ser do sujeito ao corpo, a uma carne para gozo, permitindo, ao mesmo, prescindir da sua subjetividade. A visão do corpo como unité ratière não só impede a emergência de pensamentos sobre a divisão subjetiva, porque o objetivo é gozar deste corpo, mas também se enraíza no sujeito, com essa ideia fantasmática seja ela de evidência ou de plenitude, da unanimidade de si mesmo, do eu como indivisível, como indivíduo. Gozar numa situação de unité ratière só é possível se o sujeito se limitar a ser apenas um indivíduo, um fenômeno agora extremamente frequente.

Concluímos, provisoriamente, que a prática social das perversões só é possível quando o sujeito procura agir em nome do Outro e que é o meio mais usado no estabelecimento das relações sociais. Será que existem outras maneiras de civilizar o gozo? Parece complicado estabelecer um campo de responsabilidade subjetiva que se apoia na falta do Outro (seja o Outro riscado), permitindo o desapego e, portanto, o esquecimento da ideia que existe no mundo alguém para caucioná-lo. No melhor dos casos poderemos receber "a vítima comovedora", que é o neurótico preso na errância e no mal-estar da modernidade, um "fugitivo irresponsável", como escreveu Lacan (1948/1966), e "procurar abrir novamente a via de seu sentido, em uma fraternidade discreta na medida em que somos sempre demasiadamente desiguais" (p. 124).

\section{Referências}

Debord, G. (1967). La société du spectacle. Paris: Gallimard.

Foot, P. (1997). Le problème de l'avortement et la doctrine de l'acte à double effet. In M. Neuberg. La responsabilité, questions philosophiques. Paris: PUF. (Trabalho original publicado em 1967).

Foucault, M. (1976). Histoire de la sexualité I - La volonté de savoir. Paris: Gallimard.

Freud, S. (1973). Un enfant est battu - Contribution à la connaissance de la genèse des perversions sexuelles. Névrose, psychose et perversion. Paris: PUF. (Trabalho original publicado em 1919). 


\section{ARTIGOS}

Hauser, M. et al. (2007). A dissociation between moral judgments and justifications. Mind \& Language, 22(1), 1-21.

Lacan, J. (1966). L'agressivité en psychanalyse. In Ecrits. Paris: Le Seuil. (Trabalho original publicado em 1948).

Lacan, J. (1967). Petit discours aux psychiatres ou La psychanalyse et la formation du psychiatre, conférence prononcée a St Anne. Inédit.

Lacan, J. (1975). Le séminaire. Livre XX. Encore. Paris: Le Seuil. (Trabalho original publicado em 1972-1973).

Lacan, J. (1991). Le séminaire. Livre XVII. L'envers de la psychanalyse. Paris: Le Seuil. (Trabalho original publicado em 1969-1970).

Lacan, J. (1994). Le séminaire. Livre IV. La relation d'objet. Paris: Le Seuil. (Trabalho original publicado em 1956-1957).

Lacan, J. (2006). Le séminaire. Livre XVI. D’un Autre à l'autre. Paris: Le Seuil. (Trabalho original publicado em 1968-1969).

Lacan, J. (2011). Le savoir du psychanalyste, entretiens à St Anne. Je parle aux murs. Paris: Le Seuil. (Trabalho original publicado em 1971).

Marx, K. (1993). Le capital. Livre I. Paris: PUF. (Trabalho original publicado em 1867).

Milgram, S. (1974). La soumission à l'autorité: un point de vue expérimental. Paris: Calmann-Lévy.

Ogien, R. (2011). L'influence de l'odeur des croissants chauds sur la bonté humaine et autres questions de philosophie morale expérimentale. Paris: Grasset.

Sade, D.A.F. (1993). Justine ou les malheurs de la vertu. Paris: Le livre de poche. (Trabalho original publicado em 1791).

Thomson, J.J. (1986). Killing, Letting Die, and the trolley problem. In Rights, restitution and risk. Essay in Moral theory (pp. 78-93). William Parent, Cambridge: ed., Mass., Harvard University Press. (Trabalho original publicado em 1976).

\section{Resumos}

(Social practices of perversions: modernity of bonds, social organization and moral dilemmas)

Our main purpose here is to study certain aspects of the capitalist discourse and compare them with the processes of perversion observed during clinical investigations of subjects. We then take on the dimension of morality and social construction. Experimental research on submission to authority is used as well as issues raised by moral philosophy concerning "dilemmas," in order to evaluate their effects in terms of division of the subject. The inclination to perversion seems to be an essential driving force that, in the name of the Other, brings about a jouissance that will not say its name, a denied jouissance.

Key words: Perversion, jouissance, submission, morality 
(Usages sociaux des perversions: modernité du lien, organisation sociale et dilemmes moraux)

Nous nous proposons d'étudier tout d'abord certains aspects issus du discours capitaliste en les rapprochant des processus pervers issu de la clinique du sujet, pour ensuite questionner la dimension de la morale et de la construction sociale. Nous nous appuierons sur certaines recherches expérimentales portant sur la soumission à l'autorité, ainsi que sur certaines questions posées par la philosophie morale en termes de «dilemmes», afin d'en mesurer les effets de division subjective. L'orientation perverse semble être ici un moteur essentiel faisant passer, au nom de l'Autre, une jouissance qui ne dit pas son nom, une jouissance démentie.

Mots clés: Perversion, jouissance, soumission, moralité

(Usos sociales de las perversiones: modernidad del enlace, organisación social y dilemas morales)

Proponemos examinar primero ciertos aspectos del discurso capitalista, acercándolos a procesos perversos procedentes de la clínica del sujeto, para, luego, estudiar la dimensión de la moral y de la construcción social. Para ello, utilizaremos algunas investigaciones experimentales sobre sumisión a la autoridad y algunos aspectos de la filosofia moral relacionados con los "dilemas" para tratar de apreciar sus efectos en la división subjetiva. La orientación perversa parece ser un motor esencial para permitir, en nombre del Otro, un goce que no dice su nombre, un goce desmentido.

Palabras clave: Perversión, goce, sumisión, moralidad

(Soziale perverse Praktiken: moderne Aspekte der Bindung, soziale Organisation und moralische Dilemmas)

Zu Beginn möchten wir einige Aspekte des kapitalistischen Diskurses untersuchen, um sie den perversen Prozessen der Klinik des Subjektes näherzubringen. Anschließend wird der moralische Umfang und das soziale Konstrukt hinterfragt. Dabei stützen wir uns auf einige experimentelle Untersuchungen der Autoritätshörigkeit sowie auf Fragen der moralischen Philosophie bezüglich "Dilemmas", um die Auswirkungen der subjektiven Spaltung auszuwerten. Die perverse Ausrichtung scheint hier ein wesentlicher Motor zu sein, der im Namen des Anderen einen Genuss vorgibt, der nicht seinen Namen nennt, also ein verleugneter Genuss.

Schlüsselwörter: Perversion, Genuss, Unterwerfung, Moral

Citação/Citation: Lévy, A. (2014, setembro). Práticas sociais das perversões: modernidade do laço, organização social e dilemas morais. Revista Latinoamericana de Psicopatologia Fundamental, 17(3-Suppl.), 673-685. 


\section{ARTIGOS}

Editor do artigo/Editor: Prof. Dr. Manoel Tosta Berlinck

Recebido/Received: 15.3.2014/ 3.15.2014 Aceito/Accepted: 25.4.2014 / 4.25.2014

Copyright: (C) 2009 Associação Universitária de Pesquisa em Psicopatologia Fundamental/ University Association for Research in Fundamental Psychopathology. Este é um artigo de livre acesso, que permite uso irrestrito, distribuição e reprodução em qualquer meio, desde que o autor e a fonte sejam citados / This is an open-access article, which permits unrestricted use, distribution, and reproduction in any medium, provided the original author and source are credited.

Financiamento/Funding: $\mathrm{O}$ autor declara não ter sido financiado ou apoiado / The author have no support or funding to report.

Conflito de interesses/Conflict of interest: $\mathrm{O}$ autor declara que não há conflito de interesses / The author has no conflict of interest to declare

\section{Alexandre Lévy}

Maître de conférences en Psychopathologie, LUNAM Université, Université catholique de l'Ouest - UCO - Institut de psychologie et sociologie appliquées (IPSA), Laboratoire multisite E.A. 4050: «Recherches en psychopathologie: nouveaux symptômes et lien social». 3 place André Leroy, BP 10808, 49008 ANGERS Cedex 01

France.

e-mail: alexandre.levy@uco.fr 